https://helda.helsinki.fi

\title{
Three proposals on illustrations with analysis
}

\section{Sennikov, Alexander N.}

2015-03

Sennikov , A N 2015 , ' Three proposals on illustrations with analysis ' , Taxon , vol. 64 , no.

1 , pp. 182-182 . https://doi.org/10.12705/641.14

http://hdl.handle.net/10138/156959

https://doi.org/10.12705/641.14

publishedVersion

Downloaded from Helda, University of Helsinki institutional repository.

This is an electronic reprint of the original article.

This reprint may differ from the original in pagination and typographic detail.

Please cite the original version. 


\title{
PROPOSALS TO AMEND THE CODE
}

Edited by Nicholas J. Turland \& John H. Wiersema

\section{(035-037) Three proposals on illustrations with analysis}

\author{
Alexander N. Sennikov \\ Botanical Museum, Finnish Museum of Natural History, University of Helsinki, Unioninkatu 44, P.O. Box 7, 00014 Helsinki, Finland; \\ and Herbarium, Komarov Botanical Institute of Russian Academy of Sciences, Prof. Popov str. 2, 197376 St. Petersburg, Russia; \\ alexander.sennikov@helsinki.fi
}

DOI http://dx.doi.org/10.12705/641.14

(035) Amend Art. 9.3 as follows (new text in bold, deleted text in strikethrough):

"9.3. For the purposes of this Code, original material comprises the following elements: (a) those specimens and illustrations (both unpublished and published either prior to or together with the protologue) upon which it can be shown that the description or, diagnosis, or other material validating the name (Art. 38.1(a)) was based; (b) the holotype and those specimens which, even if not seen by the author of the description or diagnosis validating the name, were indicated as types (syntypes or paratypes) of the name at its valid publication; and (c) the isotypes or isosyntypes of the name irrespective of whether such specimens were seen by either the author of the validating description or diagnosis or the author of the name (but see Art. 7.7, 7.8, and 9.10)."

It seems that the provisions of Art. 38.7 and 38.8 are not incorporated into the wording of Article 9.3. A plate with analysis is not a description or diagnosis but is acceptable as an equivalent of such. This fact is reflected in the proposed correction.

(036) Add a new Example under Art. 9.2:

"Ex. 2 bis. Adansonia grandidieri Baill. (in Grandidier, Hist. Phys. Madagascar 34: t. 79B bis, fig. 2 \& t. 79E, fig. 1. 1893) was validly published when accompanied solely by two illustrations with analysis (see Art. 38.8). Baum (in Ann. Missouri Bot. Gard. 82: 447. 1995) designated one of the sheets of Grevé 275 (flowering specimen at $\mathrm{P}$ [barcode $\mathrm{P} 00037169]$ ), presumably the very specimen from which most or all of the components of t. 79E, fig. 1 were drawn, as the lectotype of this name."
I feel it would be good to have also Art. 9.2 exemplified, especially with an example of a complicated case when the original material is not obvious and the lectotypification is not straightforward. Another purpose of this example is to show that if a name is validly published when accompanied solely by an illustration with analysis, the illustration is not automatically the holotype of the name as sometimes interpreted.

\section{(037) Add a new Example under Art. 38.9:}

"Ex. 14 bis. Chenopodium caudatum Jacq. (Icon. Pl. Rar. 2(2): t. 344. Feb-Mar 1789) was validly published when accompanied solely by a plate illustrating a complete plant broken into halves, with a separate figure of a single flower showing details aiding identification. Publication of this illustration predates the corresponding description (Jacquin, Collectanea 2: 325. Apr 1789) and diagnosis (Jacquin, Icon. Pl. Rar. 2: 12. 1795) of the species. Although the main illustration (representing a plant of Amaranthus viridis L.) is taxonomically different from the analysis (belonging to an unidentified species of Chenopodium), the name is nevertheless validly published."

This is a good example of an illustration that was taxonomically mixed but considered to represent a single species by the original author. Besides, it serves as an example of minimally sufficient compliance with the requirements of Art. 38.9 (only a single detail of the plant is illustrated).

\section{Acknowledgements}

I am grateful to Pertti Uotila (Helsinki) for the example of Chenopodium caudatum. Critical comments and editorial corrections of John Wiersema are greatly appreciated. 